\title{
Friction and Wear Behaviors of HIPS/SBS Polymer Blends
}

\author{
Münir Tasdemir and Ibrahim Miskioglu
}

\begin{abstract}
Six different high-impact polystyrene (HIPS) and polystyrene- $b$-polybutadiene- $b$-polystyrene block copolymers (SBS) (thermoplastic elastomers, Kraton D1184) blends were mixed with varying HIPS to SBS ratios. The structure of the blends were investigated by scanning electron microscopy and compared to mechanical and tribological properties as a function of SBS content. Furthermore, the elastic modulus, yield and tensile strengths, \% elongation, Izod impact resistance, hardness, Vicat softening point, heat deflection temperature, density, melt flow index and wear rate values of the polymer blends for all the HIPS to SBS ratios were determined. The addition of SBS to HIPS changed the friction coefficient and the wear rate of the blends significantly. Blends with higher SBS content showed higher wear rate than pure HIPS under dry sliding.
\end{abstract}

Index Terms-Tribological behavior, wear, mechanical properties, friction, high impact polystyrene, styrene butadiene styrene copolymer.

\section{INTRODUCTION}

Recycled plastic are potentially the most inexpensive polymer materials. However, the recycled plastics in general do not perform at sufficient level. Blending of polymers is a common technology often used to develop a product with superior mechanical properties from inexpensive polymer material with small amount of compatibilisers. The class of polystyrene- $b$-polybutadiene$b$-polystyrene (SBS) blocks copolymers and their hydrogenated and functionalized derivatives are additives that act both as impact modifiers and as compatibilisers [1]. These additives play an important role in the field of dispersed homogeneous blends.

Elastomers, so-called natural and synthetic rubbers, are widely used in automotive and other industries for their many special properties. Elastomers are usually mixed with different materials to modify their physical properties. Thermoplastic elastomers (TPE) belong to a relatively new and small class of engineering plastics.

During service, TPE behave like an elastomer (e.g., similar to vulcanized natural rubber) but, in contrast to the classical elastomers, they can be processed by means of conventional techniques and equipment utilized for all thermoplastics. This characteristic of TPE is related to their

Manuscript received March 5, 2015; revised July 23, 2015. This work was supported by the Scientific Research Project Program of Marmara University FEN-C-DRP-110215-0037.

Munir Tasdemir is with Marmara University, Technology Faculty, Metall. and Mater. Eng., 34722, Istanbul, Turkey and Chemical Engineering Faculty, Michigan Technological University, Houghton, MI, USA (e-mail: munir@marmara.edu.tr)

Ibrahim Miskioglu is with Mechanical Engineering Faculty, Michigan Technological University, Houghton, MI, USA (e-mail: imiski@mtu.edu). different type of cross-linking during processing.

Unlike classical elastomers, TPE are cross-linked by thermally labile aggregates, which melt during processing and regenerate after cooling down. [2], this is because TPE are always block copolymers comprised of "hard blocks" (forming solid crystallites or glassy regions), and "soft blocks" (imparting the elastomeric properties) [3]. The thermoplastic elastomers concern large industrial and commercial fields, as well as academic and applied research. Often the TPE are considered as being only an important part of the block copolymers, but they are present in many other polymeric materials, as shown by Holden et al. [4], [5] and Rader [6]-[8]. They are characterized by a set of properties inherent to block and graft copolymers, different blends, and some vulcanized materials. Styrene block copolymers are the most widely used TPEs, accounting for close to $45 \%$ of total TPE consumption worldwide at the close of the twentieth century.

In this study, the effects of the SBS concentration on the mechanical, thermal, tribological and morphological properties of HIPS polymer blends were investigated. To this end, HIPS/SBS blend with different HIPS to SBS ratios were produced, and the properties of the blends were investigated.

\section{EXPERIMENTAL}

Six different polymer blends were prepared. Compositions of HIPS/SBS polymer blends that were formed are given in Table I.

TABLE I: COMPOSITION OF THE HIPS/SBS POLYMER BLENDS FORMULATIONS (wt \%)

\begin{tabular}{|c|c|c|}
\hline Groups & $\begin{array}{c}\text { HIPS Content } \\
(\text { wt } \%)\end{array}$ & SBS Content (wt \%) \\
\hline 1 & 100 & - \\
\hline 2 & 90 & 10 \\
\hline 3 & 80 & 20 \\
\hline 4 & 70 & 30 \\
\hline 5 & 60 & 40 \\
\hline 6 & 50 & 50 \\
\hline
\end{tabular}

High impact polystyrene (HIPS) (porene HIPS HI650) was supplied by IRPC public company limited (Bangkok, Thailand). Its melt flow rate $\left(200^{\circ} \mathrm{C} / 5.0 \mathrm{~kg}\right)$ is $8.0 \mathrm{~g} / 10 \mathrm{~min}$. SBS (Kraton D-1184) was supplied Kraton Polymers LLC (USA). Its density is $0.938 \mathrm{~g} / \mathrm{cm}^{3}$ and Styrene rate is $30 \%$.

Sample Preparation: All materials were dried overnight at $80{ }^{\circ} \mathrm{C}$ in a vacuum oven prior to melt blending. Mechanical premixing of solid compositions was done using a LB-5601 liquid-solids blender (The PattersonKelley Co., Inc. east Stroudsburg, PA - USA) brand batch blender for $15 \mathrm{~min}$. Samples with various proportions of 
HIPS/SBS polymer blends were produced between 180-210 ${ }^{\circ} \mathrm{C}$ at 10 bar pressure, and a rotation rate of 30-33 rpm, with a Microsan extruder (Microsan Instrument Inc. Kocaeli Turkey). L/D ratio is 30 , Ǿ: $25 \mathrm{~mm}$, Polymer blends were also dried in vacuum oven at $80{ }^{\circ} \mathrm{C}$ for 24 hours after extrusion. Subsequently, test samples were manufactured by injection molding. Injection temperature was $180-210{ }^{\circ} \mathrm{C}$, pressure was 85-110 bar and screw speed was 25-30 rpm.

Mechanical Characterization: The tensile and yield strength, elongation and modulus of the compressed plates were measured by using a tensile testing machine (Zwick Z010, Germany) according to ASTM D638 at room temperature and crosshead speed of $50 \mathrm{~mm} / \mathrm{min}$. For every composition, five samples were tested, and the averages of the five measurements were reported. The hardness test was done according to the ASTM D2240 method with Zwick hardness tester. To investigate fracture behavior, Izod impact test (notched) was done at room temperature according to the ASTM D256 method with Zwick B5113 impact tester (Zwick, Germany). Flow behavior testing of all the mixtures was done according to ISO 1133 standard with Zwick 4100 MFI equipment. Heat deflection temperature (HDT) and Vicat softening point tests were done according to ISO 75 and ISO 307 standard with determined by CEAST 6521 (Ceast SpA, Italy) HDT-Vicat test equipment. Determination of density was done according to ISO 2781 test standard.



(a)

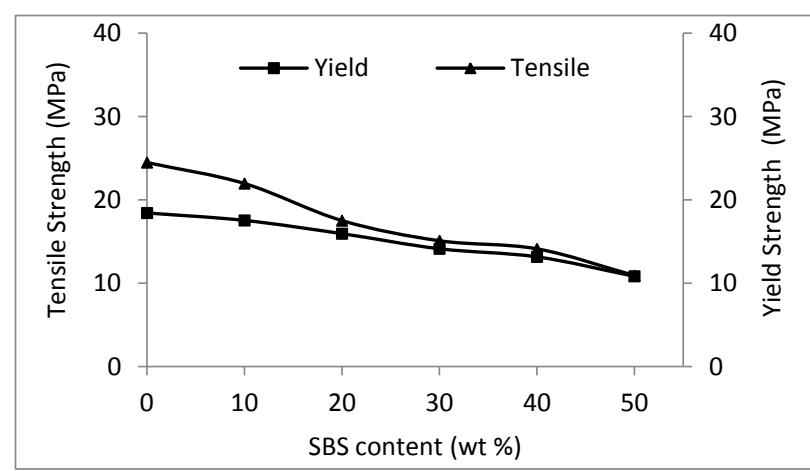

(c)

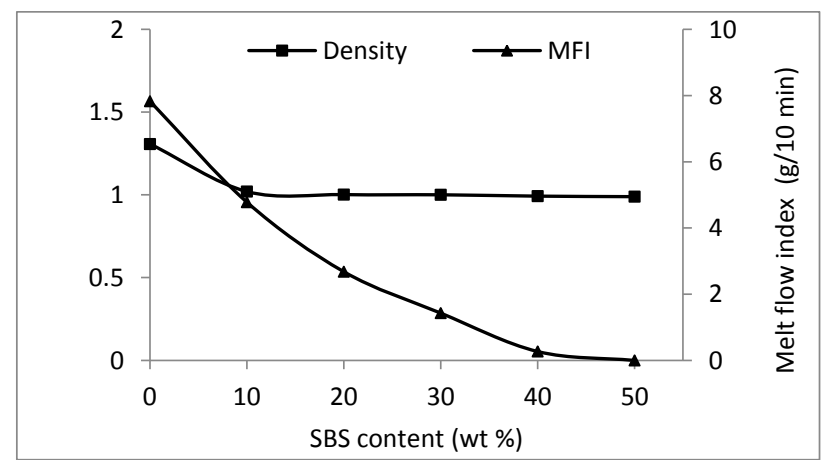

(e)

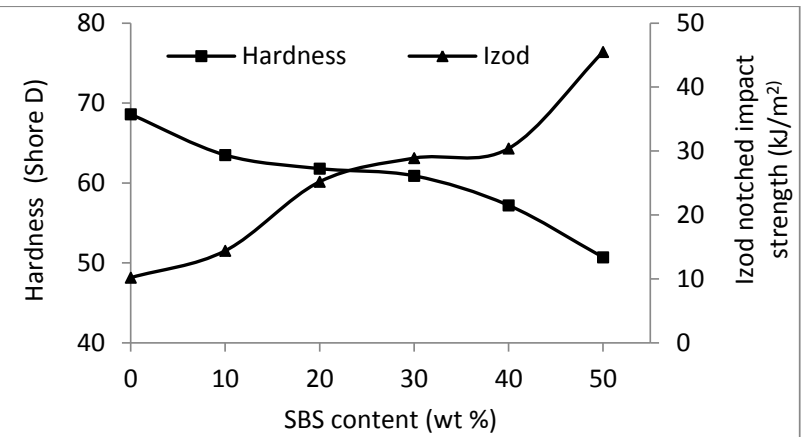

(b)

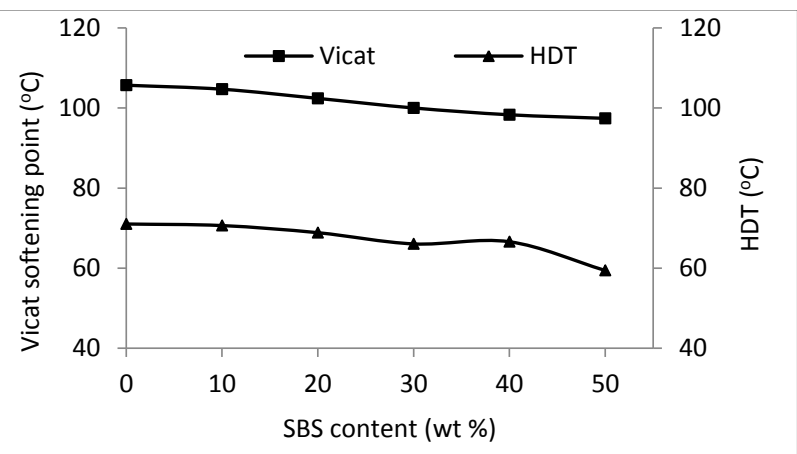

(d)



(f)

Fig. 1. Mechanical properties of the HIPS/SBS polymer blends.

Tribological Tests: Static and dynamic coefficient of friction test was done according to the ISO 8295 method with Devotrans friction coefficient measurement equipment. The dimensions of the tested specimens were $80 \times 200 \times 4$ $\mathrm{mm}$ and the dimensions of the sled specimens were $63 \times 63 \times 4 \mathrm{~mm}$. Speed was selected as $100 \mathrm{~mm} / \mathrm{min}$.

Static Coefficient of Friction $\left(\mu_{s}\right)$ : The force increases linearly to a maximum which represents the static frictional force $F_{S}$. Measurements made at a high friction drag permit the dynamic coefficient of friction to be calculated, but not the static coefficient of friction. The static coefficient of friction $\mu_{s}$ is given by the equation,

$$
\mu_{s}=F_{S} / F_{P}
$$

where $F_{S}$ is the static frictional force, expressed in Newton, $F_{P}$ is the normal force exerted by the mass of the sled, 
expressed in Newton $(=1.96 \mathrm{~N})$.



A1) $50 \mathrm{~mm} / \mathrm{min}$

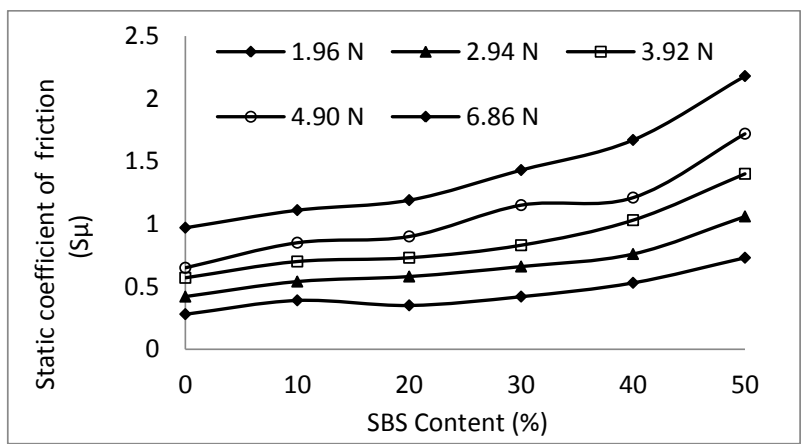

B1) $100 \mathrm{~mm} / \mathrm{min}$

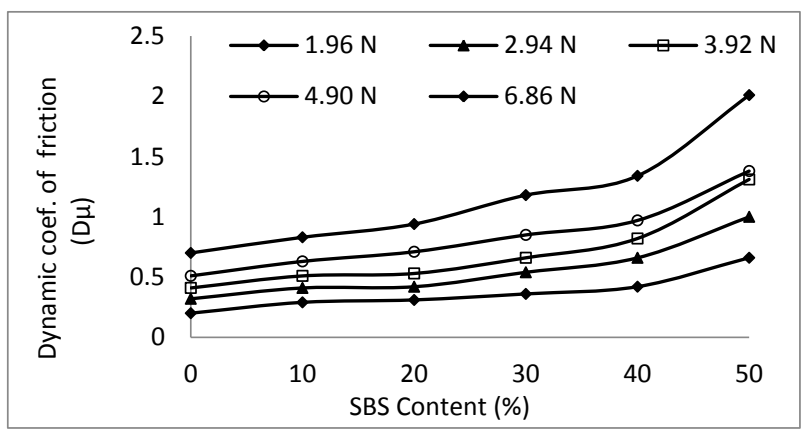

C1) $150 \mathrm{~mm} / \mathrm{dak}$

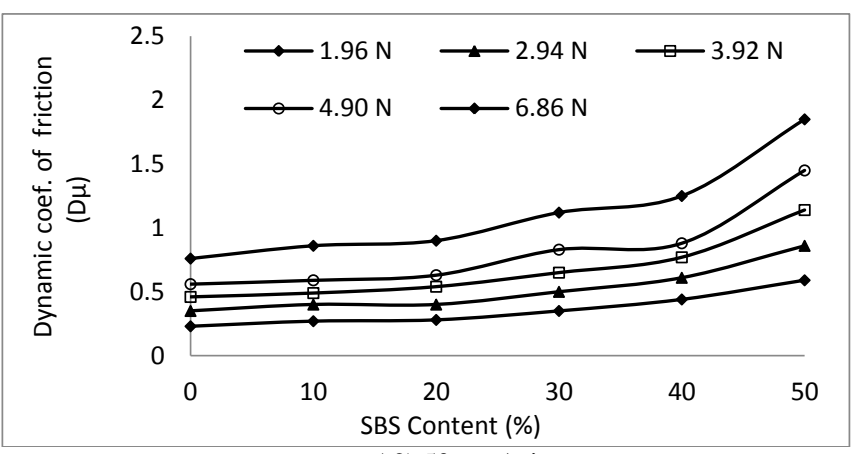

A2) $50 \mathrm{~mm} / \mathrm{min}$



B2) $100 \mathrm{~mm} / \mathrm{min}$

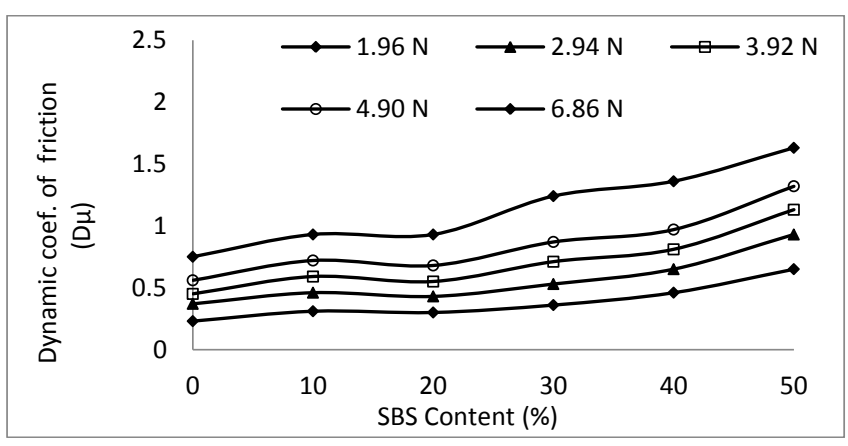

C2) $150 \mathrm{~mm} / \mathrm{dak}$

Fig. 2. Friction properties of the HIPS/SBS polymer blend.

Dynamic Coefficient of Friction $\left(\mu_{D}\right)$ : The friction force acting during the sliding motion often differs from the constant value which would exist in an ideal situation due to secondary effects related to increasing path length. The dynamic frictional force $F_{D}$ is the average force over the first $6 \mathrm{~cm}$ of motion after the start of relative motion between the surfaces in contact, neglecting the static force peak $F_{s}$. The dynamic frictional force using the equation,

$$
\mu_{D}=F_{d} / F_{P}
$$

where $F_{D}$ is the dynamic frictional force, expressed in Newton, $F_{P}$ is the normal force exerted by the mass of the sled, expressed in Newton (N) [9]. Tribological tests were at room temperature under 1.92, 2.94, 3.92, 4.9 and $6.86 \mathrm{~N}$ load values for friction (at 50, 100 and $150 \mathrm{~mm} / \mathrm{min}$ sliding speed).

Wear Rate: The wear tests were done according to the DIN 53516 method with Devotrans DA5 (Devotrans quality control test equipment Istanbul-Turkey) abrasion test equipment (sand paper \#60 and $0,32 \mathrm{~m} / \mathrm{s}$ abrasion speed). The thickness of the test specimens was $7.0 \mathrm{~mm}$ and diameter was $15.5 \mathrm{~mm}$. Cylinder rotational speed was selected as $40 \mathrm{rpm}$ and normal load $\left(F_{N}\right)$ of 5-10-15 and $20 \mathrm{~N}$ were used. Total sliding distance $(L)$ was $40 \mathrm{~m}$. The mass loss of the samples $(\Delta m)$ was measured after the wear process, and the specific wear rates (Ws) were calculated using the following equation:

$$
W s=(\Delta m) / \rho . F_{N} \cdot L\left(\mathrm{~cm}^{3} / \mathrm{Nm}\right)
$$

where $\Delta m$ is the specimen's mass loss, $\rho$ is the density of specimen, $F_{N}$ is the normal load applied, and $L$ is the total sliding distance. The friction coefficients and wear rates reported in the present study were the averages of three separate tests.

Microscopy: The fractured surfaces of the HIPS/SBS polymer blends were coated to thickness of 10-12 nm of a gold $(\mathrm{Au})(80 \%) /$ palladium $(\mathrm{Pd})(20 \%)$ alloys to prevent electrical charging by Polaron SC 7620 (Gala Instrumente $\mathrm{GmbH}$, Germany). The surfaces of the prepared samples were observed by the JEOL-JSM 5910 LV (JEOL Ltd., Japan) scanning electron microscopy (SEM) at an acceleration voltage of $20 \mathrm{kV}$. 


\section{RESULT AND DISCUSSION}

Properties of the HIPS/SBS Polymer Blend: Mechanical properties of the HIPS/SBS polymer blends are given in Fig. 1. The relationship between the elasticity modulus (a measure for stiffness) and the elongation at break of the HIPS/SBS polymer blend is shown in the Fig. 1. (a). Since SBS polymer has much lower stiffness values than the HIPS matrix, the elasticity modulus of the HIPS/SBS polymer blend decreased as the SBS concentration increases from 0 to $50 \mathrm{wt} \%$. On the other hand, elongation at break values are increased as the SBS concentration increased from 0 to $50 \mathrm{wt} \%$. This observation is in line with the fact that the ductility of the material increases with the decrease in its stiffness. The minimum elongation at break is observed at pure HIPS (Group 1).

The relationship between the SBS content and the hardness of the polymer blend is shown in Fig. 1(b) The hardness of the blends decreased an increase weight percentage of SBS (from 0 to $50 \mathrm{wt} \%$ ). Fig. 1(b) also illustrates the effect of SBS on the Izod impact strength (notched) of HIPS. The impact strength of blends increased as the SBS concentration increased from 0 to $50 \mathrm{wt} \%$. To sum up the above it is clear that SBS loading have an important effect on the blend properties which can be improved or reduced with changing SBS loading. The relationship between the SBS content and tensile and yield strength of HIPS/SBS blends is shown in the Fig. 1(c). Ultimate tensile and yield strength of blends shows a decrease as the SBS concentration increases from 0 to 50 wt $\%$. Thermal properties of the HIPS/SBS polymer blends are given in Fig. 1(d). The HDT and Vicat experiment were started at room temperature with a heating rate of $120^{\circ} \mathrm{C} / \mathrm{h}$ and under a load of $1.8 \mathrm{MPa}$ and $1 \mathrm{Kg}$ respectively. With the addition of SBS in HIPS has been a change in values. The vicat values of the HIPS/SBS blend decreased with an increase weight percentage of SBS from 0 to $50 \mathrm{wt} \%$.

For example, the vicat softening temperature of virgin HIPS and HIPS/SBS (50 wt \%) polymer blends were $105^{\circ} \mathrm{C}$ and $97^{\circ} \mathrm{C}$ respectively. Similar situation was seen in HDT values. The HDT of virgin HIPS and HIPS/SBS (50 wt \%) polymer blends were $71^{\circ} \mathrm{C}$ and $59^{\circ} \mathrm{C}$ respectively. The relationship between the SBS content and melt flow index and density of HIPS/SBR blends is shown in Fig. 1(e). Melt flow index of HIPS/SBR polymer blends decreased as the SBS concentration increased from 0 to $50 \mathrm{wt} \%$. The effects of applied load and SBS content on the tribological behaviors of HIPS/SBS blends were examined. The values of applied load-wear rate relationship are shown in Figure 1(f). It can be seen that the wear rate of blends increase with increasing applied load and SBS content. It should be noted that there was significant jump in the wear rate as the SBS content changed from $20 \%-30 \%$. A similar observation was also made with the increasing load that the wear rate increased more rapidly when the load was changed from $15 \mathrm{~N}$ to $20 \mathrm{~N}$. These observations suggest that there is a critical SBS content between $20 \mathrm{wt} \%$ and $30 \mathrm{wt} \%$ and critical load between $15 \mathrm{~N}$ and $20 \mathrm{~N}$ after which the wear rate increases rapidly. It suggests that this is a critical load and SBS content for transition from mild to severe wear of the blends. More data will be needed to determine these critical points.
Friction Coefficients of the HIPS/SBS: Polymer Blend Friction performance of all blends considered in this study is shown in Fig. 2 for speeds 50, 100 and 150 mm/min.

At each speed and dynamic friction coefficients were determined under normal loads of 1.96, 2.94, 3.92, 4.9 and $6.86 \mathrm{~N}$. It is seen that the load and SBS content had a great effect on the static and dynamic friction coefficient of the blend. Fig. 2 A1-A2 shows that the friction static and dynamic coefficient of friction of pure HIPS is much lower than that of HIPS/SBS (60/40) or HIPS/SBS (50/50) blends at any loads at $50 \mathrm{~mm} / \mathrm{min}$. Same situation was seen HIPS/SBS (60/40) or HIPS/SBS (50/50) blends at any loads at $100 \mathrm{~mm} / \mathrm{min}$ and $150 \mathrm{~mm} / \mathrm{min}$ (Fig. 2 B1-B2, C1-C2) So, as the load increased, the static and dynamic friction coefficient of all blends increased for all speeds.

Morphological Properties of the HIPS/SBS: Polymer Blends: The fracture surfaces of the polymer blends were examined via SEM in an attempt to correlate the mechanical properties to the microstructural characteristics. With addition of SBS to the HIPS, the adhesion and distribution of the present phases were considerably enhanced as well (Fig. 3). These micrographs verify the brittle to ductile transition of the blends as the SBS content is increased.



Fig. 3. SEM micrographs revealing the appearance of the fracture surfaces of the HIPS/SBS polymer blends.

\section{CONCLusions}

The tribological properties of HIPS/SBS blends were studied at different loads and speed under dry sliding. The effects of SBS content on the wear and friction behavior were discussed. From the above investigations, it can be concluded that the wear mechanism of HIPS/SBS blend is related with its composition that is as the SBS component increases, the wear behavior of blend gradually changes from HIPS to SBS. With the addition of SBS to the HIPS, the wear rate and friction coefficient significantly changed. The blends with the addition a low level content of SBS showed lower wear rate while the blend with a high level content of SBS had higher wear rate. The applied load had an effect on the wear rate of HIPS/SBS blend. The results also showed that the coefficients of friction increases linearly with the load increase. From the mechanical aspect, the higher the HIPS content, the higher the hardness of the blend, and the stronger resistance to the plowing action of the asperities on the counter face against sample surface 
during sliding.

\section{ACKNOWLEDGMENT}

This work has been supported by the Marmara University, Scientific Research Research Projects Committee (FEN-CYLP-110215-0037).

\section{REFERENCES}

[1] Z. Jelcic, T. Holjevac-Grguric, and V. Rek, "Mechanical properties and fractal morphology of high-impact polystyrene/poly(styrene- $b$ butadiene- $b$-styrene) blends," Polymer Degradation and Stability, vol. 90, no. 2, pp. 295-302, 2005

[2] M. Tasdemir and E. Ulug, "Mechanical, morphological and thermal properties of SEBS, SIS and SBR-type thermoplastic elastomers toughened high impact polystyrene," Polymer-Plastics Technology and Engineering, vol. 51, pp. 164-169, 2012.

[3] S. Fakirov, Handbook of Condensation Thermoplastic Elastomers, Wiley-VCH verlag Gmbh \& Co., p. 1, 2005.

[4] G. Holden, N. R. Legge, R. P. Quirk, and H. E. Schroeder, Thermoplastic Elastomers, Hanser-Garner Publications, Munich, 1996.

[5] G. Holden, Understanding Thermoplastic Elast., Hanser-Garner Publications, Munich, 2000.

[6] C. Rader, "Thermoplastic elastomers," Rubber Technology Special Topics, Rubber Div, 2003, pp. 415-433.

[7] C. P. Rader, The Rubber-Thermoplast Continuum, 2002.
[8] C. P. Rader, "Thermoplastic elastomers," Elastomer Technology Compounding and Testing for Performance, 2001, pp. 264-283.

[9] Plastics-Film and sheeting-Determination of the Coefficients of Friction, 1995.

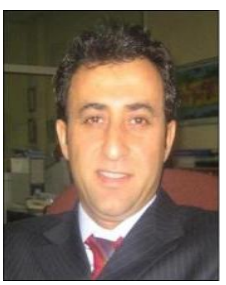

Munir Tasdemir is an assistant professer of metallurgy and materials engineering, Faculty of Technology, Marmara University. He was born in 1970. He graduated from Marmara University, Turkey (B.Sc., M.Sc and Ph.D degress in materials science and engineering). His research fields are polymer science, polymer alloys and blends, polymer characterization. He has participated in several researches projects in international and national.

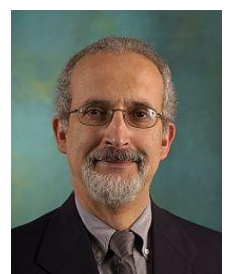

Ibrahim Miskioglu is an assistant professer of Mechanical Engineering and Engineering Mechanics Faculty, Michigan Tech, University. He received his $\mathrm{PhD}$ degree from Iowa University in USA. His research fields are engineering mechanics, experimental stress analysis, composite materials. He has participated in several researches projects in international and national. 